\title{
Axial Field Permanent Magnet DC Motor With Powder Iron Armature
}

\author{
Suleiman M. Abu Sharkh and Mohammad T. N. Mohammad
}

\begin{abstract}
The paper describes a double-gap axial field permanent magnet (PM) dc motor whose double-layer armature wave winding is constructed of copper strips. It investigates the performance of two machines using powder iron and lamination steel materials as armature teeth. Tests are conducted to evaluate the motor torque and speed curves as well as their efficiency under different loads. Finite element analysis (FEA) and equivalent circuit models are used to determine the levels of the magnetic saturation in the motors; calculate torque, inductance, and electromotive force (EMF); and determine the distribution of losses in the machine. The results show that the powder iron armature machine has lower back EMF and torque constants, and is less efficient than the steel laminations machine, which is due to the lower permeability and saturation flux density of the powder iron material.
\end{abstract}

Index Terms-Axial field, dc motor, permanent magnet (PM) motor, powder iron.

\section{INTRODUCTION}

A XIAL field machines can offer the advantages of slim short axial length and a high power-to-weight ratio compared to radial gap machines, but tend to have larger diameters and higher inertia [1]. A stackable multidisk construction is also possible to produce high output when the available diameter is limited [2], [3]. This makes this type of machine attractive in many applications. Small brushless permanent magnet (PM) axial field machines are used extensively in consumer appliances such as camcoders, video players, compact disk players, and personal stereos [4], [5]. Axial gap brushless motors have also been used as bicycle hub motor [6] and as traction motors in solar powered vehicles [7].

Brushed-dc axial field machines have been used or proposed for use in many applications including electric vehicle traction, car radiator fan motor, [8], [9], and ship propulsion [10]. In these applications, axial field topology was chosen due to its high efficiency and compactness.

In this paper, the motor under investigation is a double-axial air gap PM dc machine. It is essentially a variant of the Lynch Motor described in [11]. The motor has been used successfully in many applications, including electric boats and light electric vehicles. The main feature of the Lynch motor, which makes it different from other axial-gap dc machines such as those described in [8]-[10] is that it uses a copper strip winding with

Manuscript received September 12, 2005; revised May 7, 2006. This work was supported by R. Fletcher and the Lynch Motor Company. Paper no. TEC00319-2005.

S. M. Abu Sharkh is with the School of Engineering Sciences, University of Southampton, Highfield, Southampton SO17 1BJ, U.K. (e-mail: suleiman@soton.ac.uk).

M. T. N. Mohammad is with Electro Magnetix Ltd., Falmer, Brighton BN1 9SB, U.K. (e-mail: m.mohammad@elektro.co.uk).

Digital Object Identifier 10.1109/TEC.2007.895870

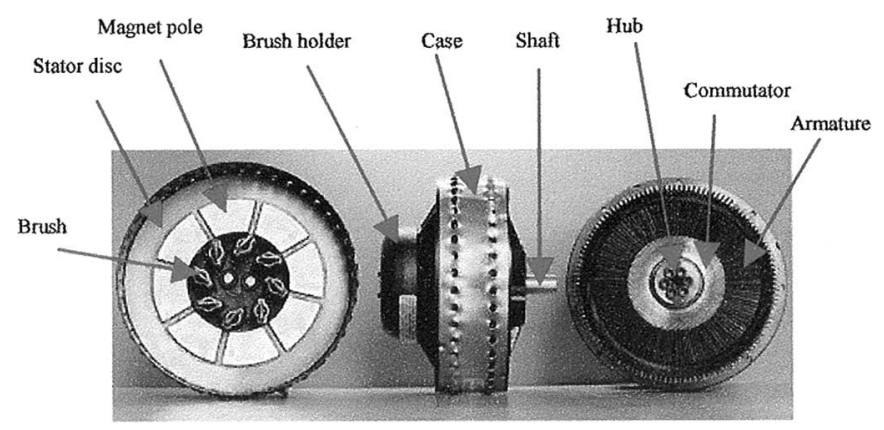

Fig. 1 Photograph of the motor.

iron inserted between the copper strips to form teeth. The motors described in [8] and [9] use an ironless armature constructed from stranded copper winding. Due to its armature construction and good cooling, the Lynch motor is capable of high power output, with a torque density of $2.5 \mathrm{~N} \cdot \mathrm{m} / \mathrm{kg}$, which is five times that of the industrial radial-gap dc motors.

However, the current armature construction method using steel laminations is very labour intensive (see Section II). It involves stacking and gluing seven different sized small strips of steel laminations, which are wrapped with Nomex paper before insertion between the copper strips to form teeth.

To reduce the amount of manual labour, this paper proposes the use of powder iron net-shaped wedges to replace the steel lamination teeth. The paper describes a motor that was constructed using powder iron teeth and compares its performance, using tests and FEA, to a motor using steel laminations.

\section{DESCRIPTION OF THE MOTOR}

A photograph of the motor is shown in Fig. 1; an enlarged photograph of the armature is shown in Fig. 2. and a crosssection of the motor is shown in Fig. 3. The nominal rating of the eight-pole motor is $10.5 \mathrm{~kW}, 28 \mathrm{Nm}, 3600 \mathrm{rpm}$ at $60 \mathrm{~V}$, $200 \mathrm{~A}$. In many applications, the motor may be supplied from 12 or $24 \mathrm{~V}$ batteries and run at lower speeds, but it should be derated as the effectiveness of air ventilation and cooling worsens at low speeds. The overall diameter of the motor is $210 \mathrm{~mm}$, and the axial length including the shaft is $132 \mathrm{~mm}$.

The motor comprises of two PM stator disks with air gaps of $1.65 \mathrm{~mm}$ on either side of the rotating armature. The attractive forces between magnets of opposite polarity on the two-stator disks, which are separated by a cylindrical metal case, effectively hold the motor together.

The rotating disc-armature is constructed using copper strip pairs of conductors, as shown in Fig. 4. These are stamped, bent, powder coated, and assembled into a thin rotary disc, as shown 


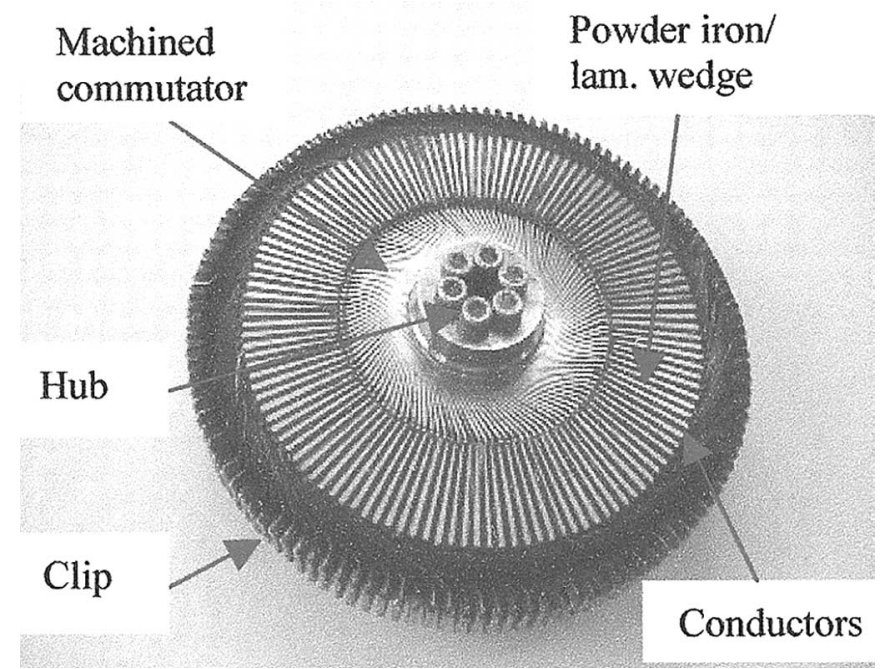

Fig. 2. Photograph of the armature.

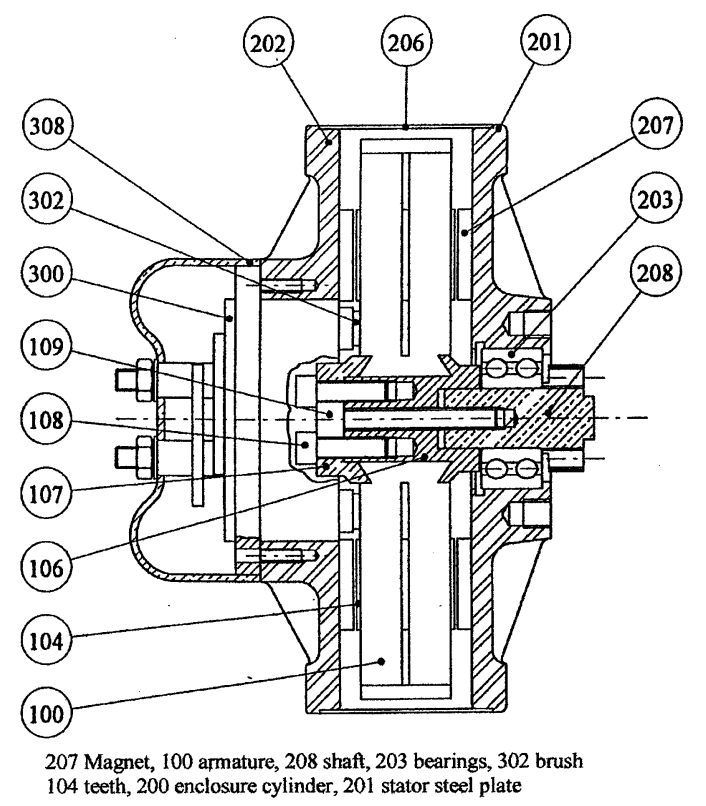

Fig. 3. Cross section of the motor: 207-magnet, 100 - armature 208 - shaft, 203-bearings, 302-brush, 104 - teeth, 200 - enclosure cylinder, and 201stator steel plate.

in Fig. 2. to form a double layer wave winding. The approximate cross-sectional dimensions of the conductor are $0.82 \times 12 \mathrm{~mm}^{2}$. The active length of a conductor is approximately $30 \mathrm{~mm}$. A total of 127 pairs of conductors are joined at the top end by clips to form 127 coils of a two-layer wave winding. The common bottom ends of conductors are dovetail-joined into the centre of the armature (the hub) as shown in Fig. 3.

Looking downwards on the armature in Fig. 2, the conductors are packed tightly by wedges of steel laminations or powder iron inserted between the adjacent conductor strips to form teeth. The wedges are wrapped individually with $0.35-\mathrm{mm}$ Nomex insulating tape. The strip copper construction results in a highslot copper fill factor of about 56\%. The lamination wedges consist of groups of seven pieces of 0.3 -mm-thick Unisil 30M5 (a)

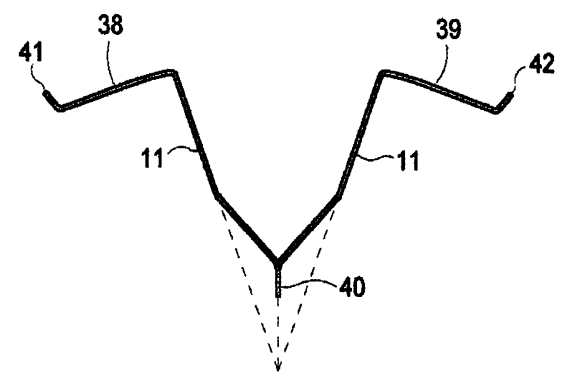

(b)

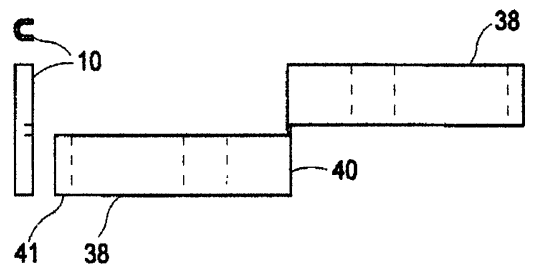

(c)

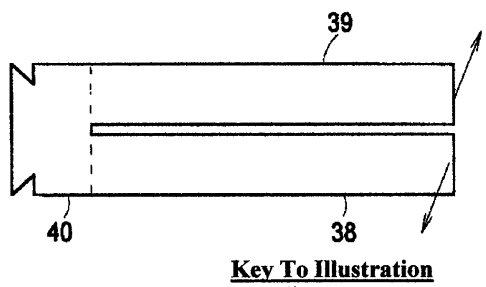

(d)

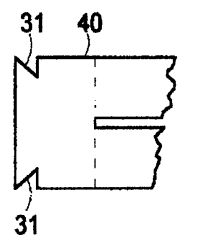

10. Clips

11. Conductors

31. Dovetail ends of conductors

38. First part of conductor

39. Second part of conductor

40. Joining member

41. First end of conductor

42. Second end of conductor

Fig. 4. Pair of copper strip conductor making up the armature.

laminations of different length as shown in Fig. 5. The powder iron teeth supplied by GKN, have the same overall dimensions as the lamination teeth as shown in Fig. 5. A micrograph of the powder iron material is shown in Fig. 6, which illustrates the insulation between individual particles of iron. The $B-H$ curves of the powder iron and laminations are compared in Fig. 7.

The copper strips and the lamination wedges are held together by a carefully selected two-part epoxy resin material (Araldite CY1300GB, 100 parts by volume; Hardner HY932, 35 parts by volume). The resin's thermal expansion coefficient and temperature ratings are selected to match the operating temperature and expansion properties of the armature. The mix of resin and hardner is poured to fill the gaps between the wedges and copper strips, with care taken not to fill the gaps between the commutator segments or the endwindings, as that prevents air circulation in these parts of the machine; thus, impairing the cooling (see the following paragraph). The resin is then cured for $4 \mathrm{~h}$ at $80^{\circ} \mathrm{C}$ followed by $3 \mathrm{~h}$ at $100{ }^{\circ} \mathrm{C}$. After the curing process, the surface of the wedges are skimmed.

The edges of the inner sections of the copper strip coils are subsequently machined to form the commutator as shown in Fig. 2. The brush gear holds eight spring-loaded silver graphite brushes connected to terminals as shown in Fig. 8. The brushes are oriented to be parallel to the commutator segments. They 


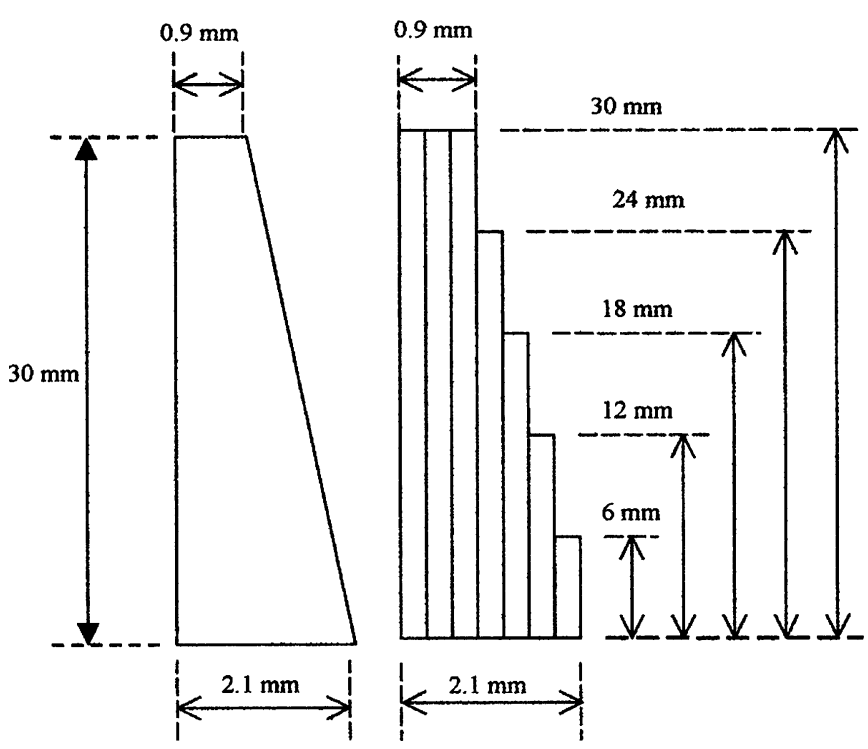

Fig. 5. Dimensions of powder iron teeth (left) and lamination teeth (right).

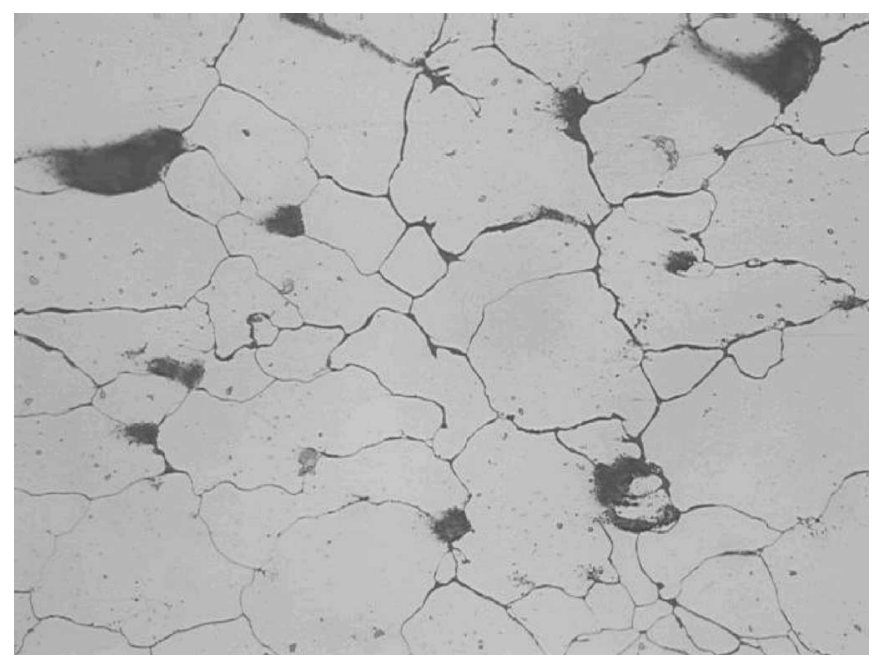

Fig. 6. Microstructure of powder iron material.

are nominally aligned with interpolar stator axes such that the electromotive force (EMF) in the short-circuited coils is approximately zero; but in practice, they are nominally aligned with the interpolar axis and then, adjusted manually to minimize noload current when the machine is running in a certain direction. Hence, they may not be in exact alignment with the interpolar axes. The brush contact surface is normally made to have a width of approximately 1.5 commutator segments.

The copper strips of the armature endwinding and commutator are separated from each other to encourage airflow around the conductors for more effective cooling. Ventilation holes are also machined into the stator plates and the cylindrical casing. The rotation of the armature produces sufficient airflow to cool the motor; the higher the speed of rotation, the better the cooling.

The magnets used were San Huan Lucky N-36M NdFeB grade with remenance flux density of $1.2 \mathrm{~T}$, and a coercivity of $899 \mathrm{kA} / \mathrm{m}$ at $20{ }^{\circ} \mathrm{C}$. The 4-mm-thick magnets have an inner

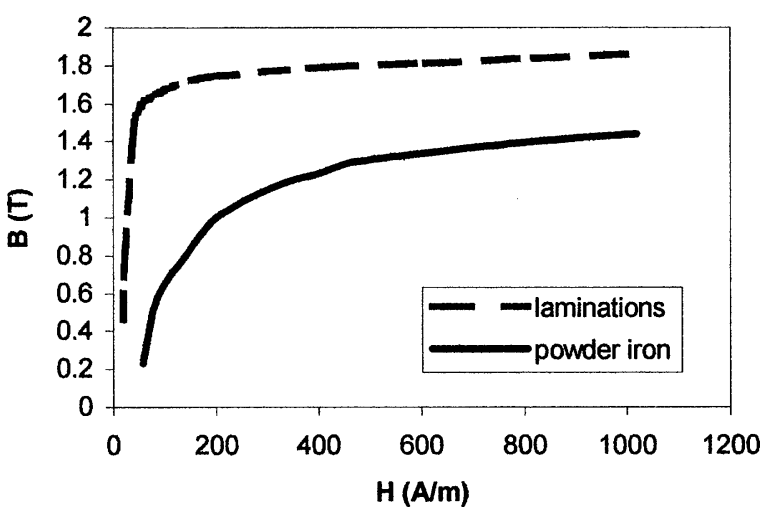

Fig. 7. $B-H$ curves of lamination and powder iron materials.

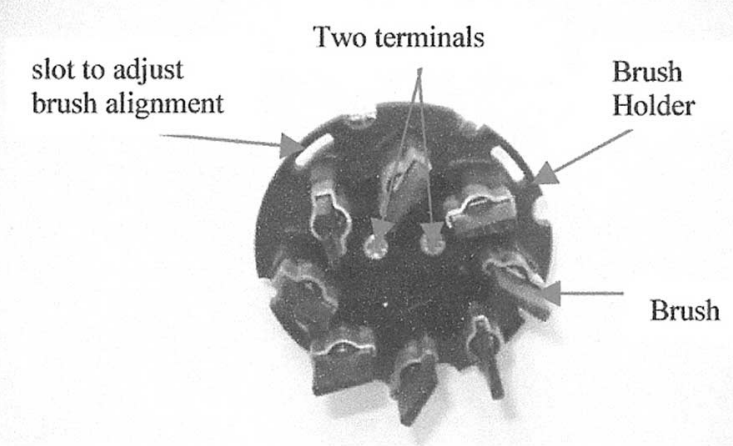

Fig. 8. Photograph of the brush holder.

radius of $45 \mathrm{~mm}$ and an outer radius of $75 \mathrm{~mm}$. There is a small parallel gap of $3 \mathrm{~mm}$ between the adjacent magnet poles.

\section{TEST REsults}

Tests were carried out using a motor generator test rig in which two similar motors are coupled together and mounted such that their shafts axis is vertical. This arrangement is possible due to the slim axial length of the machines compared to its diameter. The bottom motor is bolted to a bedplate, while the stator of top generator is restrained from rotation by a torque arm. The output power of the generator is recirculated to power the motor, with the excess power supplied by a small power supply (the primary power supply) as shown in Fig. 9. The secondary power supply in Fig. 9 controls the generator current and hence the mechanical load on the motor shaft. The experimental errors are as follows: 1) speed error is $\pm 1 \mathrm{rpm}$; 2) torque error is $\pm 0.04 \mathrm{Nm}$; 3 ) current error is $\pm 0.1 \% \pm 0.2 \mathrm{~mA}$; 4) voltage error is $\pm 0.1 \% \pm 1 \mathrm{mV}$. Measurements were made after the machines reached steady state and the readings stabilized. Most of the measurements were also repeated several times.

Friction and windage losses were measured by replacing the generator machine with an especially constructed machine using wooden blocks to replace the magnets. The mechanical power input to such a machine was a direct measurement of windage and friction. No-load iron losses were calculated by subtracting friction and windage losses from the mechanical power needed to drive an unloaded generator with magnets. Copper loss and 


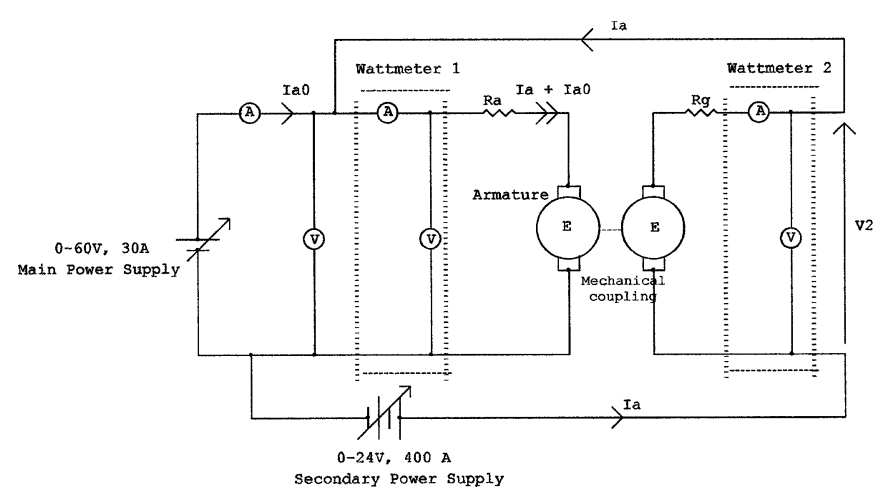

Fig. 9. Circuit diagram of the test rig.

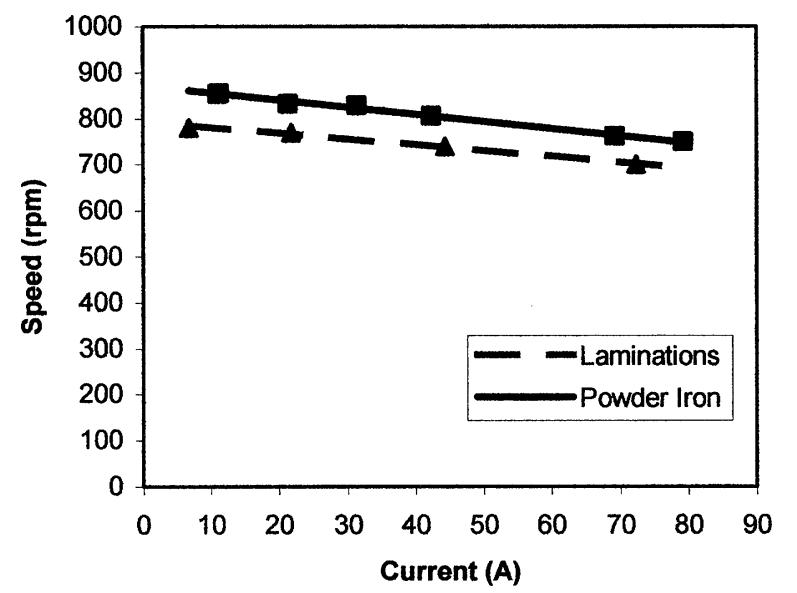

Fig. 10. Speed versus current.

brush electrical losses were estimated in the usual manner from load tests.

The results for both motors are shown in Figs. 10-12, which show performance comparisons of speed, torque, and efficiency versus input current at $12 \mathrm{~V}$. The figures show that the powder iron motor runs faster, and has lower power, torque production, and efficiency than the motor with lamination teeth wedges. These results are expected (see Section IV) as the powder iron used has a lower permeability than steel laminations. This results in a reduction of flux in the machine, thus reducing the back EMF and torque constants, which increases the armature current for a given load, thereby increasing the ohmic loss and reducing its efficiency.

\section{Finite ElEment AND Circuit ANALYsis}

Ideally, 3-D FEA is needed to analyze such a machine, but it tends to be very time consuming-requiring thousands of hours to simulate a few seconds [13]. In this paper, 2-D FEA was, therefore, used to analyze the motors described. The use of 2-D FEA to analyze the axial-gap machines is well established [7], [10], [12], [13]. An equivalent linear model of the machine with a pole pitch equal to that measured at the average radius is usually used. The depth of the model is taken to be the active length of the machine, which usually equals the radial length of the magnet. Figs. 13 and Figs. 14 show such models for the powder iron and the lamination machines, respectively.

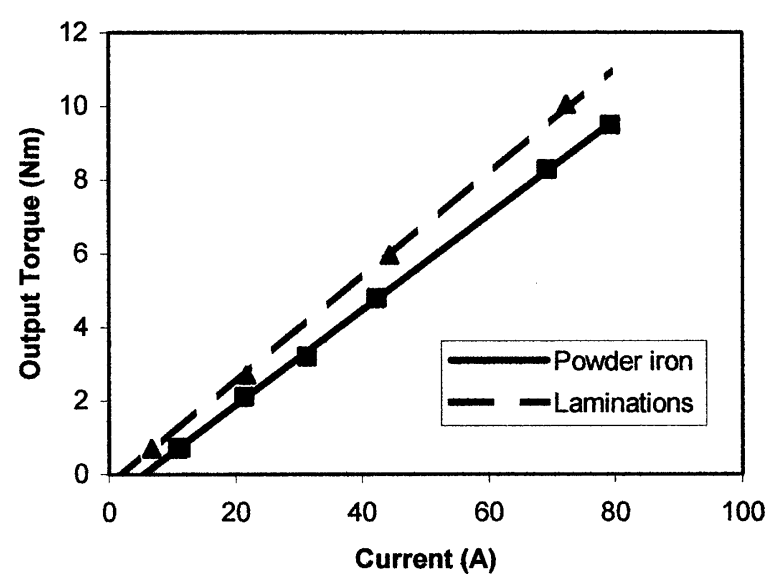

Fig. 11. Torque versus current.

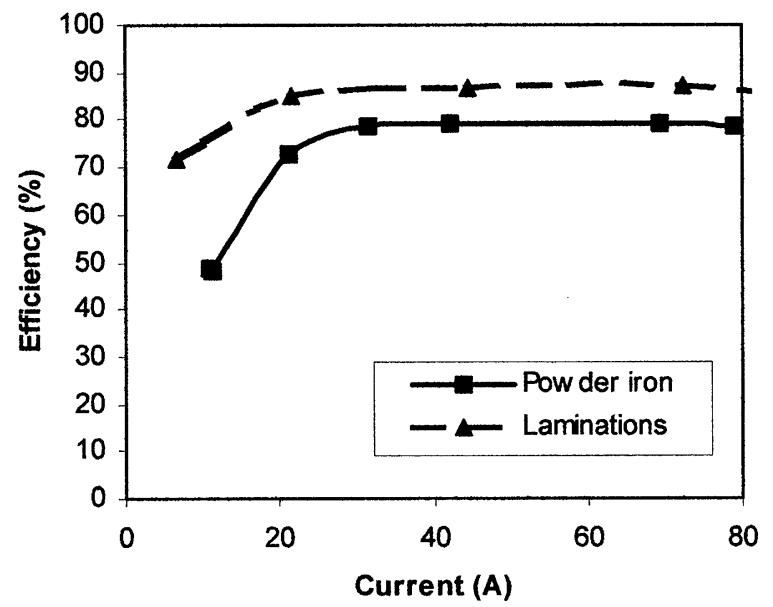

Fig. 12. Efficiency versus current.

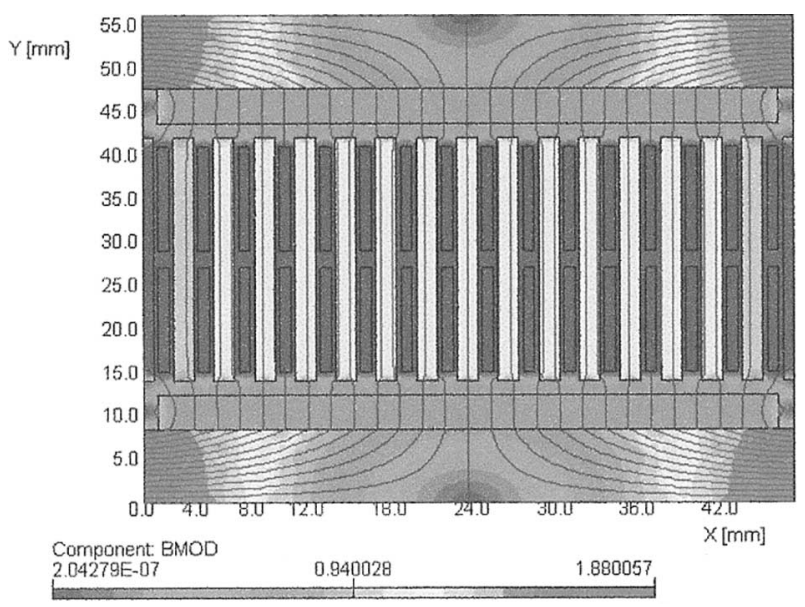

Fig. 13. No-load 2-D FEA flux distribution in powder motor.

2-D models are known to underestimate the effect of flux leakage from one magnet to the next. The proportion of the leakage flux increases with decreasing radius [8]. For this reason, the authors investigated the effect of flux leakage for a number of linear 2-D FEA models with different magnet widths corresponding to different machine section radii. Electromagnetic 


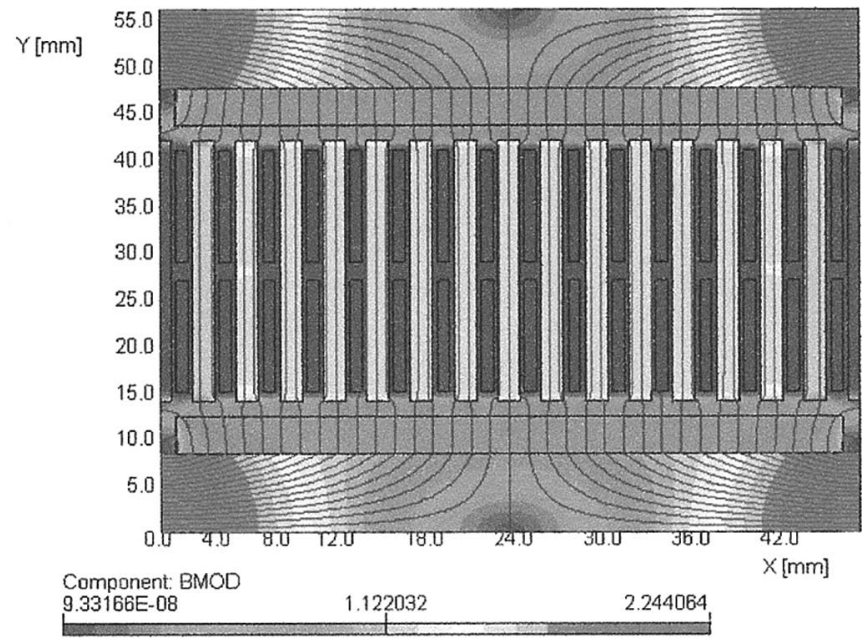

Fig. 14. No-load 2-D FEA flux distribution in laminations motor.

torque and EMF calculated from the combination of these models (considering the machine being made up of 10 2-D slices of differing pole pitch values) was found to be very close to the values calculated from one 2-D linear model at the average radius, which suggest that the variation of flux leakage with radius is not very significant, and a 2-D model at the average radius is sufficient. However, 2-D models by their nature do not account for radial leakage flux from the edge of the magnets to the steel plates. Representative 2-D FEA linear models suggest that this leakage flux is of the order of $15 \%$. Some data evaluated from a 3-D analytical model that supports these findings is provided in [8]. The efficacy of 2-D FEA models is further supported by experimental measurements and analytical results provided in [5].

The FEA models were used to study flux distribution in the machines, and calculate electromagnetic torque using the Maxwell stress tensor method. They were also used to calculate the EMF and inductance of each coil, as well as the mutual inductance between a coil and all the other coils. Due to the large number of conductors, only two magnetostatic solutions are needed to evaluate the EMF and inductance values. A noload solution is used to calculate the EMF from flux linkages calculated at different conductor positions. Inductance is calculated from a magnetostatic model with magnetization of the magnets set to zero, and their relative permeability set equal to the recoil permeability, which neglects the effect of saturation.

The EMF and inductance data were used in a circuit model of the machine in which each coil $x$ is represented by an equivalent circuit of $\operatorname{EMF} E_{x}(\theta)$ in series with a resistance $R$, self inductance $L_{x x}$, and all the mutual inductances $L_{x y}$ according to the following equation:

$$
\begin{aligned}
V_{x} & =i_{x} R+L_{x x} i_{x}+\sum_{y} L_{x y} i_{y}+E_{x}(\theta)+E_{b}(\theta) \\
E_{x}(\theta) & =\omega K_{x}(\theta) \\
T & =\sum_{x} i_{x} K_{x}(\theta)
\end{aligned}
$$

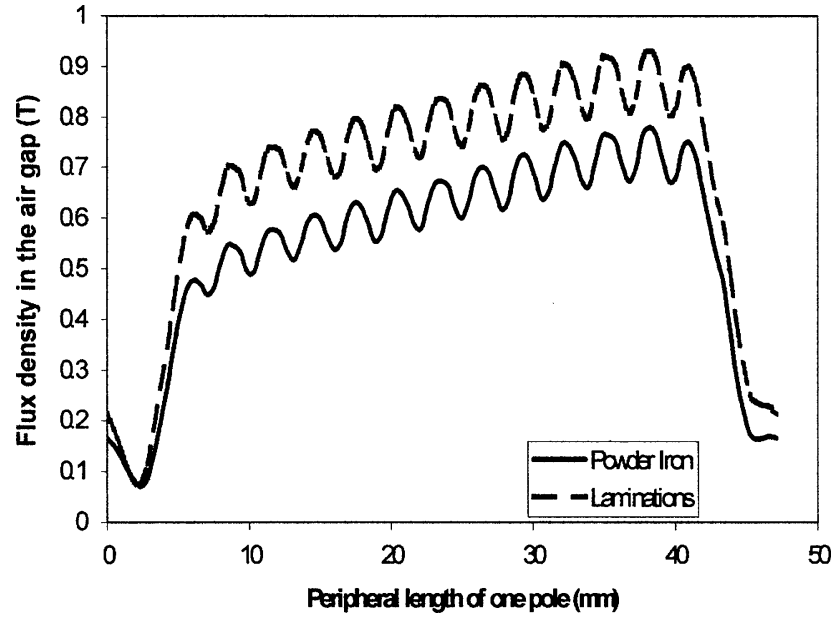

Fig. 15. Gap flux density.

where $\theta$ is the electrical angle of the rotor, $i_{x}$ is the coil current, $\omega$ is the rotor angular speed, $T$ is the motor electromagnetic torque, and $V_{x}$ is the coil voltage determined according to the position of the brush. The commutator is represented by a switching circuit, allowing for variable brush/commutator contact width, resistance, and arcing using the voltage $E_{b}(\theta)$. The arc voltage is determined from an empirical formula representing the relationship between arc voltage, current, and the gap between the brush and the commutator. Such an empirical formula was derived from representative arc-voltage-discharge curves between a brush and a commutator segment as described in [14] and [15]. The timing of switching can be adjusted to allow for different brush widths and brush position advance or misalignment. Matlab/Simulink SimPowerSytems was used to solve the equivalent circuit model, which enables the calculation of instantaneous currents in the coils for given de voltage as well as voltages across switches. Using such a circuit simulation, it is possible to calculate instantaneous torque, ohmic losses, and brush losses, including brush circulating current loss. Core loss, which is calculated from empirical formulae for the used steel and powder materials, is added as part of the mechanical load model (which includes brush friction) incorporated in the overall Simulink model of the machine.

Fig. 13 shows a typical FEA model showing flux distribution on no-load in the powder machine. Fig. 14 shows the no-load flux distribution in the lamination machine. It is clear that the level of flux in the lamination machine is significantly higher than in the powder machine, which is due to the poorer permeability and saturation induction of the powder material as shown in Fig. 7. It is also noticed that the lamination machine shows significant saturation in the stator back of core.

Fig. 15 shows the flux density in the gap of both the machines under full load of $200 \mathrm{~A}$ input current $(100 \mathrm{~A} /$ conductor), which confirms the lower flux density in the powder machine and explains its inferior performance that was observed experimentally.

The results of the FE analysis at a load of 200 A are summarized in Table I, which confirms that the lower permeability 
TABLE I

RESULTS OF FEA

\begin{tabular}{lcccc}
\hline Armature & $\begin{array}{l}\text { Inductance, } \\
\mu \mathrm{H}\end{array}$ & $\begin{array}{l}\text { Torque } \\
\text { at 200 } \\
\mathrm{A}, \mathrm{Nm}\end{array}$ & $\begin{array}{l}\text { Average } \\
\mathrm{T}\end{array}$ & $\mathrm{B}_{\mathrm{g}}$, \\
\hline Laminated & 0.25 & 33 & 0.74 \\
Powder iron & 0.21 & 27 & 0.68 \\
\hline
\end{tabular}

of the powder iron reduces flux and torque. The circuit model torque and efficiency calculations agree with the experimental results to within experimental and model uncertainty.

\section{COST COMPARISON}

Using the powder iron wedges instead of laminations cuts the lamination assembly cost, which takes approximately $2-3 \mathrm{~h} /$ machine if done manually by a skilled worker. However, for the iron powder machine to achieve a performance similar to that of the lamination machine, the magnet thickness needs to be increased approximately by $50 \%$ to $6 \mathrm{~mm}$, which offsets the labor cost saving.

\section{CONCLUSION}

The paper described the construction of a double axial-gapbrushed dc motor. The double-layer armature wave winding is made of copper strips. The paper investigated the performance of two machines using powder iron and lamination steel materials as armature teeth.

Test and finite element results show that the performance of the powder iron motor is inferior to the motor using steel laminations, due to the lower permeability and lower saturation flux density of powder iron. The powder machine has lower back EMF and torque constants, lower gap flux density, and lower efficiency than the lamination machine.

The performance of the powder iron machine can be improved to match the lamination machine by increasing the magnet thickness by approximately $50 \%$ for the machine described in this paper, which offsets the lamination assembly cost saving.

\section{ACKNOWLEDGMENT}

The powder iron material was provided by GKN Inc.

\section{REFERENCES}

[1] K. Sitapati and R. Krishnan, "Performance comparisons of radial and axial field permanent-magnet brushless machines," IEEE Trans. Ind. Appl., vol. 37, no. 5, pp. 1219-1226, Sep./Oct. 2001.

[2] H. Takano, T. K. Itoh, A. Sakuta, and T. Hirasa, "Optimum values for magnet and armature winding thickness for axial-field permanent magnet brushless dc motors," IEEE Trans. Ind. Appl., vol. 28, no. 2, pp. 350-357, Mar./Apr. 1992

[3] S. Etmad, "High speed permanent magnet axial field generator," paper presented at Inst. Electr. Eng. Sem. Permanent Magn. Mater.-Fundam, Design Appl., London, U.K., Jul. 2000.
[4] F. Profumo, F. J. Eastham, A. Tenconi, and G. Gianolio, "Plastic electric motors: A viable solution for axial flux machines," Proc. IEEE Int. Symp. Ind. Electron., vol. 1, no. 1, pp. 1-10, Jul. 2002.

[5] J. K. Lee, "Measurements of magnetic fields in axial field motors," IEEE Trans. Magn., vol. 28, no. 5, pp. 3021-3023, Sep. 1992.

[6] P. R. Johansen, D. Patterson, C. O'Keefe, and J. Swenson, "The use of an axial flux permanent magnet in-wheel direct drive in an electric bicycle," Renewable Energy, vol. 22, pp. 151-157, 2001.

[7] D. Patterson and R. Spee, "The design and development of an axial flux permanent magnet brushless dc motor for wheel drive in a solar powdered vehicle," IEEE IAS Conf. Rec., Denver, U.K., vol. 1, Oct. 1994, pp. 188195.

[8] P. Campbell, "Principles of a permanent-magnet axial-field dc machine," Proc. Inst. Electr. Eng., vol. 121, pp. 1489-1494, 1974.

[9] A. Corbett and M. T. Mohammad, "The disk armature motor and its applications," Inst. Electr. Eng. Conf. Publication 136, Small Electrical Machines, pp. 59-62, 1992.

[10] J. M. Bailey, R. A. Hawsey, D. S. Daniel, and R. J. Thomas, "Design of a high power density permanent magnet axial gap dc motor," in Proc. IEEE Southeastcon., New Orleans, LA, vol. 2, Apr.1990, pp. 480-484.

[11] C. Lynch, "Rotor for electrical machines and machines incorporating such motors," U.K. Patent GB218413, 1986.

[12] S. M. Abu Sharkh and M. T. N. Mohammad, "Finite element analysis of an axial-gap permanent magnet dc motor," in Proc. Inst. Electr. Eng. Int. Conf. Comput. Electromagn., Bournmouth, U.K., 2002.

[13] R. J. Hill-Cottingham, P. C. Coles, D. Rodger, and H. C Lai., "Finite element modeling of an axial flux PM machine," in Proc. 2nd Inst. Electr. Eng. Int. Conf. Power Electron., Machines Drives, Edinburgh, U.K., vol. 2, 2004, pp. 552-555.

[14] H. Ayrton, The Electric Arc. $\quad$ London: Electrician, 1902.

[15] S. M. Abu Sharkh, "Influence of contact dynamics and point-on-wave switching on arc and contact phenomena in medium duty switches" Ph.D. Thesis, University of Southampton, Southampton, U.K., 1994.

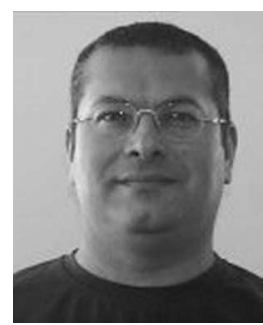

Suleiman M. Abu Sharkh received the B.Eng. and $\mathrm{Ph} . \mathrm{D}$. degrees in electrical engineering from the University of Southampton, Highfield, Southampton, U.K., in 1990 and 1994, respectively.

Currently, he is a Senior Lecturer in the School of Engineering Sciences, University of Southampton. He is also the Director of HiT Systems Ltd. He has published over 60 papers in academic journals and conference proceedings. His research interests include electrical machines and drives.

Dr. Abu Sharkh is a member of the Institution of Electrical Engineers (IEE).

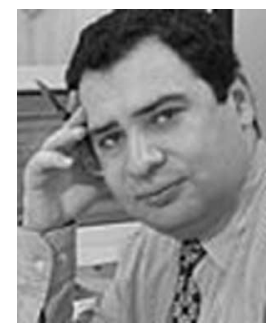

Mohammad T. N. Mohammad received the B.Sc. degree from Albalqa University, Alsalt, Jordan, and the Ph.D. degree in electromechanical engineering from the University of Southampton, Highfield, Southampton, U.K., in 2004.

$\mathrm{He}$ is currently with Electro Magnetix Ltd., Brighton, U.K. His current research interests include electrical machines and drive. 